American Journal of Biochemistry and Biotechnology 3 (1): 1-9, 2007

ISSN 1553-3468

(C) 2007 Science Publications

\title{
Unconventional Approach for Demineralization of Deproteinized Crustacean Shells for Chitin Production
}

\author{
N.S. Mahmoud, A.E. Ghaly and F. Arab \\ Process Engineering and Applied Science Department, Dalhousie University \\ Halifax, Nova Scotia, Canada B3J 2X4
}

\begin{abstract}
Chitin is a versatile environmentally friendly modern material. It has a wide range of applications in areas such as water treatment, pulp and paper, biomedical devices and therapies, cosmetics, membrane technology and biotechnology and food applications. Crustacean waste is the most important chitin source for commercial use. Demineralization is an important step in the chitin purification process from crustacean waste. The conventional method of demineralization includes the use of strong acid (commonly $\mathrm{HCl}$ ) that harms the physiochemical properties of chitin, results in a harmful effluent wastewater and increases the cost of chitin purification process. The current study proposes the use of organic acids (lactic and acetic) produced by cheese whey fermentation to demineralize microbially deproteinized shrimp shells. The effects of acid type, demineralization condition, retention time and shells to acid ratio were investigated. The study showed that the effectiveness of using lactic and/or acetic acids for demineralization of shrimp shells was comparable to that of using hydrochloric acid. Using organic acids for demineralization is a promising concept, since organic acids are less harmful to the environment, can preserve the characteristics of the purified chitin and can be produced from low cost biomass such as cheese whey. In addition, the resulted organic salts from the demineralization process can be used as a food preservative and/or an environmentally friendly de-icing/anti-icing agents.
\end{abstract}

Key words: Crustacean waste, chitin, demineralization, organic acids, food preservatives

\section{INTRODUCTION}

Chitin is a versatile environmentally friendly modern material. It is a naturally occurring high molecular weight linear homopolysaccharide composed of $\mathrm{N}$-acetyl-D-glucoseamine residues in $\beta(1-4)$ linkage. Li et al. ${ }^{[1]}$ reported that chitin and chitin derivatives are biodegradable and biocompatible natural polymers that have been used in virtually every significant segment of the economy (e.g. water treatment, pulp and paper, biomedical devices and therapies, cosmetics, biotechnology, agriculture, food science and membrane technology). The number and variety of industrial uses are growing rapidly. Brzeski ${ }^{[2]}$ reported that the potential applications of chitin and its derivatives have been estimated at over 200 .

Chitin can be found in a variety of species in both the animal and plant kingdoms. It is present in amounts varying from trace quantities up to about $40 \%$ of the body weight of the organism. The crustacean waste is the most important chitin source for commercial use due to its high chitin content and ready availability ${ }^{[3-5]}$. However, chitin present in the crustacean waste is associated with proteins, minerals (mainly calcium carbonate) and lipids including pigments. Therefore, chitin purification passes through several steps: (a) the grinding of the shells to a uniform particle size, (b) protein separation (deproteinization), (c) mineral removal (demineralization) and (d) elimination of pigments and lipids.

The conventional demineralization process of crustacean waste is costly and causes environmental problems. Hydrochloric acid is the most commonly used chemical in the demineralization of crustacean waste. The use of this strong acid: (a) harms the physiochemical properties of chitin, (b) results in a harmful effluent wastewater and (c) increases the cost of chitin purification process. Percot et al. ${ }^{[6]}$ reported that using $\mathrm{HCl}$ for the demineralization of chitin results in detrimental effects on the molecular weight and the degree of acetylation that negatively affects the intrinsic properties of the purified chitin. The authors elaborated on the importance of the optimization of the extraction process parameters $(\mathrm{pH}$, time, temperature and solids to acid ratio) in order to minimize chitin degradation and bring the impurity levels down to the satisfactory level for specific applications. Therefore, a less harmful cheaper demineralization process is needed.

The current study proposes the use of a novel demineralization process in which organic acids (lactic and acetic) are used. Using organic acids such as lactic and/or acetic acids for the demineralization process is a

Corresponding Author: A.E. Ghaly, Process Engineering and Applied Science Department, Dalhousie University, Halifax, Nova Scotia, Canada B3J 2X4, Tele: (902) 494-6014, Fax: (902) 423-2423 
promising idea since organic acids: (a) can be produced from low cost biomass such as cheese whey, (b) are less harmful to the environment, (c) can preserve the characteristics of the purified chitin and (d) the resulting organic salts from the demineralization process can be used as an environmentally friendly deicing/anti-icing agents and/or as preservatives. The objectives of this study were to: (a) evaluate the effectiveness of organic acids (lactic and acetic) to demineralize microbially deproteinized shrimp shells, (b) study the effects of retention time and shells to acid ratio on the performance of the demineralization process using organic acids and (c) determine the amount of the major acetate and lactate salts that results from the demineralization process.

\section{MATERIALS AND METHODS}

\section{Shrimp shells}

Northern Pink Shrimp (Pandalus borealis) shell waste was used in this study. Pandalus borealis is commonly fished in the North Atlantic both on the East Coast of Canada and the West Coast of Norway. Shahidi and Synowiecki ${ }^{[7]}$ reported that the processing discards of these shrimp may account for up to $80 \%$ of the original weight of the material.

The shrimp shells were obtained from Ocean Nutrition Ltd. of Bedford, Nova Scotia. The material came from a shell processing plant in Mulgrave, Nova Scotia. These shrimp were caught in the fall of 2001, as part of the offshore Northern Shrimp Fishery by a vessel owned by Clearwater Fine Foods Inc. and then individually quick-frozen on board the vessel. They were stored frozen in this manner until arrival at a cooking/peeling plant operated by St. Anthony Seafoods Ltd., St. Anthony, Newfoundland where they were cooked in boiling salt water for 10 minutes. Following cooking, the shrimp were sent to automated peeling machines where the shell and meat portions were separated. The shell material was collected and dried in large kiln dryers in Mulgrave before shipping for further processing. The obtained shrimp shells were stored at about $-25^{\circ} \mathrm{C}$ in the storage facility (Associated Freezers of Canada, Dartmouth, Nova Scotia) till needed.

Before subjecting the shrimp shells to demineralization the shells were first microbially deproteinized. The deproteinization process took place in a $1.8 \mathrm{~L}$ drum bioreactor. The fungus Aspergillus niger (ATCC 16513) was used for the deproteinization process according to the procedures described by Mahmoud $^{[8]}$. Ground autoclaved shrimp shell material collected after $120 \mathrm{~h}$ of deproteinization was used. The deproteinized shells were washed thoroughly several times with deionized distilled water until the wash water was clear and dried in an oven (Isotemp Oven, Model 655F, Fisher Scientific, Montreal, Quebec, Canada) at $60{ }^{\circ} \mathrm{C}$ before use in this experiment.

\section{Reagents}

The chemicals used in performing the demineralization process included $1 \mathrm{~N}\left(36.46 \mathrm{~g} \mathrm{~L}^{-1}\right) \mathrm{HCl}, 1.7 \mathrm{~N}(61.98 \mathrm{~g}$ $\left.\mathrm{L}^{-1}\right) \mathrm{HCl}, 75.6 \mathrm{~g} \mathrm{~L}^{-1}$ lactic acid and $75.0 \mathrm{~g} \mathrm{~L}^{-1}$ acetic acid solutions. The 1 and $1.7 \mathrm{~N} \mathrm{HCl}$ solutions were prepared by the addition of $82.8 \mathrm{~mL}$ and $140.8 \mathrm{~mL}$ concentrated (36.5-38.0\%) $\mathrm{HCl}$ (Fisher Scientific, Montreal, Quebec, Canada) to a $1000 \mathrm{~mL}$ volumetric flasks and bringing the solutions to $1000 \mathrm{~mL}$ each with distilled-deionized water. The lactic acid solution was prepared by the addition of $73.54 \mathrm{~mL}(85 \% \mathrm{w} / \mathrm{w})$ DLlactic acid (Sigma-Aldrich Canada Ltd., Oakville, Ontario, Canada) to de-ionized distilled water and making up the solution to $1000 \mathrm{~mL}$. The acetic acid solution was prepared by the addition of $71.57 \mathrm{~mL}$ $(99.8 \% \mathrm{w} / \mathrm{w})$ glacial acetic acid (Fisher Scientific, Montreal, Quebec, Canada) to de-ionized distilled water and making up the solution to $1000 \mathrm{~mL}$.

\section{Experimental procedures}

Four sets of experiments were carried out using $1 \mathrm{~L}$ beakers. The first two sets were used to study the effects of acid type as well as demineralization condition on efficiency of the demineralization process. The third and fourth sets were used to study the effects of retention time (contact time between organic acid solutions and crude chitin) and shells to acid ratio on the efficiency of the demineralization process.

Effects of acid type and demineralization conditions: In the first two sets of experiments, two organic acids (lactic and acetic acids) and one mineral acid (hydrochloric acid) were used to demineralize microbially deproteinized shells under two demineralization conditions. The concentrations of acids used in the demineralization process as well as the demineralization conditions were chosen based on data available in the literature (Table 1).

Tango and Ghaly ${ }^{[9]}$ attained a high lactic acid concentration of $75.6 \mathrm{~g} \mathrm{~L} \mathrm{~L}^{-1}$ from cheese whey fermentation using an immobilized packed bed of Lactobacillus helveticus in continuous mode at $36 \mathrm{~h}$ retention time and initial lactose concentration of $100 \mathrm{~g}$ $\mathrm{L}^{-1}$. Based on this study, a lactic acid solution of $75.6 \mathrm{~g}$ $\mathrm{L}^{-1}$ concentration was synthesized and used for demineralization. Yang et al. ${ }^{[10]}$ attained a high acetate concentration of $75.0 \mathrm{~g} \mathrm{~L} \mathrm{~L}^{-1}$ from cheese whey fermentation using recycle fed-batch immobilized coculture of Lactococcus lactis and Clostridium formicoaceticum. Based on this study, an acetic acid solution of $75.0 \mathrm{~g} \mathrm{~L}^{-1}$ concentration was synthesized and used for the demineralization study.

The first set of experiments was carried out according to the demineralization procedure (A) described by Zakaria ${ }^{[11]}$. 
Table 1: $\quad$ Studied demineralization conditions

\begin{tabular}{lll}
\hline Parameter & \multicolumn{2}{l}{ Demineralization condition } \\
& $\mathrm{A}^{\mathrm{a}}$ & $\mathrm{B}^{\mathrm{b}}$ \\
\hline Concentration $^{\mathrm{c}}$ & $1 \mathrm{~N}$ & $1.7 \mathrm{~N}$ \\
Temperature & $100{ }^{\circ} \mathrm{C}$ & Room temperature \\
Retention time & $1 \mathrm{~h}$ & $6 \mathrm{~h}$ \\
Shells to acid ratio & $1: 50$ & $1: 10$ \\
\hline${ }^{\mathrm{a}}$ According to Zakaria & \\
${ }^{\mathrm{b}}$ According to Ghanem et $_{\text {al. }}{ }^{[12]}$ & \\
${ }^{\mathrm{c}}$ In case of using HCl otherwise $75.6 \mathrm{~g} \mathrm{~L}^{-1}$ lactic acid and $75.0 \mathrm{~g} \mathrm{~L}^{-1}$ \\
acetic acid were used.
\end{tabular}

In this procedure, $1 \mathrm{~g}$ of microbially deproteinized shells (MDS) was mixed with $50 \mathrm{~mL}$ acid $\left(36.46 \mathrm{~g} \mathrm{~L}^{-1}\right.$ $\mathrm{HCl}, 75.60 \mathrm{~g} \mathrm{~L}^{-1}$ lactic acid, $75.00 \mathrm{~g} \mathrm{~L}^{-1}$ acetic acid) and placed in a water bath at $100{ }^{\circ} \mathrm{C}$ for $1 \mathrm{~h}$. The second set of experiments was carried out according to the procedure (B) described by Ghanem et al. ${ }^{[12]}$. In this procedure, $1 \mathrm{~g}$ of microbially deproteinized shells was mixed with $10 \mathrm{~mL}$ acid $\left(61.98 \mathrm{~g} \mathrm{~L}^{-1} \mathrm{HCl}, 75.60 \mathrm{~g} \mathrm{~L}^{-1}\right.$ lactic acid and $75.00 \mathrm{~g} \mathrm{~L}^{-1}$ acetic acid) and placed on a stir plate $\left(\right.$ Thermix ${ }^{\circledR}$ Stirrer Model 120MR, Fisher Scientific, Montreal, Quebec, Canada) at room temperature $\left(24{ }^{\circ} \mathrm{C}\right)$ for $6 \mathrm{~h}$. Samples were then collected for analysis.

Effect of retention time: From the previous sets of experiments it was found that demineralization conditions did not have a significant effect on the minerals removal efficiency. Therefore, in this set of experiments demineralization condition B was used since it saves energy (performed at room temperature) and acid (uses less amount of acid). The effect of reducing the retention time from 6 to $2 \mathrm{~h}$ on the minerals removal efficiency of the microbially deproteinized shells was studied. Lactic acid and acetic acid solutions (75.6 and $75.0 \mathrm{~g} \mathrm{~L}^{-1}$ concentration, respectively) were used. The crude chitin along with either the lactic acid or the acetic acid solution were placed in a beaker and mixed continuously using a stir plate $\left(\right.$ Thermix $^{\circledR}$ Stirrer Model 120MR, Fisher Scientific, Montreal, Quebec, Canada) for the required retention time at room temperature $\left(24^{\circ} \mathrm{C}\right)$. Samples were then collected for analysis.

Effect of crude chitin to acid ratio: From the previous set of experiments, it was found that reducing the retention time from 6 to $2 \mathrm{~h}$ caused a slight decrease in the minerals removal efficiency. Therefore, in this set of experiments, the effect of crude chitin to acid solution ratio $(1: 10,1: 20$ and $1: 30 \mathrm{~g}$ crude chitin: $\mathrm{mL}$ acid solution) on the minerals removal efficiency of microbially deproteinized shells at $2 \mathrm{~h}$ retention time was studied. Lactic acid and acetic acid solutions (75.6 and $75.0 \mathrm{~g} \mathrm{~L}^{-1}$ concentration, respectively) were used. The crude chitin along with the acid solution was placed in a beaker and mixed continuously using a stir plate $\left(\right.$ Thermix $^{\circledR}$ Stirrer Model 120MR, Fisher Scientific, Montreal, Quebec, Canada) for $2 \mathrm{~h}$ at room temperature $\left(24{ }^{\circ} \mathrm{C}\right)$. Samples were then collected for analysis.

\section{Experimental analyses}

Moisture content: A known weight of each sample was placed in a preweighed aluminum dish. The dish and contents were then placed in an oven (Isotemp Oven, Model 655F, Fisher Scientific, Montreal, Quebec) at $105{ }^{\circ} \mathrm{C}$ for 24 hours. The aluminum dish along with the dried sample was first placed in a desiccator to cool down and then weighed. The moisture content was determined as follows:

$\mathrm{MC}=\frac{\mathrm{W}_{\mathrm{ws}}-\mathrm{W}_{\mathrm{ds}}}{\mathrm{W}_{\mathrm{ws}}} \times 100$

Where

MC is the moisture content (\%)

$\mathrm{W}_{\mathrm{ws}}$ is the weight of the wet sample ( $\mathrm{g}$ )

$\mathrm{W}_{\mathrm{ds}}$ is the weight of the dry sample (g)

Ash content: Deproteinized shells as well as purified chitin (demineralized shells) were filtered under suction through a Buchner funnel with coarse porosity filter paper (Reeve Angel Grade 202, Whatman Inc., Clifton, NJ, USA). The recovered solids were washed thoroughly several times using deionized-distilled water and dried in an oven (Isotemp Oven, Model 655F, Fisher Scientific, Montreal, Quebec, Canada) at $60^{\circ} \mathrm{C}$ for $24 \mathrm{~h}$. The dried deproteinized samples and the purified chitin samples were analyzed for their ash content. Samples were placed in a muffle furnace (Isotemp ${ }^{\circledR}$ Muffle Furnace model 186A, Fisher Scientific, Montreal, Quebec, Canada) at $700{ }^{\circ} \mathrm{C}$ for 2 hours. The sample was taken from the muffle furnace and placed in a desiccator to cool down and then weighed. The ash content was determined as follows:

$\mathrm{AC}=\frac{\mathrm{W}_{\mathrm{ds}}-\mathrm{W}_{\mathrm{a}}}{\mathrm{W}_{\mathrm{ds}}} \times 100$

Where

$\mathrm{AC}$ is the ash content (\%)

$\mathrm{W}_{\mathrm{a}}$ is the weight of the organic component $(\mathrm{g})$

Minerals: The demineralized shell material (purified chitin) was filtered under suction through a Buchner funnel with coarse porosity filter paper (reeve angel grade 202, Whatman Inc., Clifton, NJ, USA). The recovered solids were washed thoroughly several times using deionized-distilled water and dried in an oven (Isotemp Oven, Model 655F, Fisher Scientific, Montreal, Quebec, Canada) at $60^{\circ} \mathrm{C}$ for $24 \mathrm{~h}$. The dried purified chitin samples were analyzed for their minerals content. Quantitative trace element analyses were done using an Atomic Absorption Spectrophotometer (SpectrAA 55B, Varion, Mulgrave, Victoria, Australia) in the Minerals Engineering Center, Dalhousie University, Halifax, Nova Scotia. For magnesium, calcium, manganese, potassium, sodium, iron and copper analyses, the samples were first digested with hydrochloric, nitric, hydrofluoric and perchloric acids (30, 10,10 and $5 \mathrm{~mL} \mathrm{~g}^{-1}$ sample, respectively) in a 
closed vessel at a temperature of $100{ }^{\circ} \mathrm{C}$ and then the elements were determined by flame atomic absorption with detection limit of $1 \mathrm{ppm}$. For silicon, aluminum and titanium analyses, $1 \mathrm{~g}$ of the sample was fused with a flux of lithium metaborate and lithium tetraborate and leached with 1:9 nitric acid. Sulfur was determined with Leco Sulfur analyzer along with Leco Induction Furnace (Leco Corporation ST. Joseph, HI, USA). Phosphorus was determined as $\mathrm{P}_{2} \mathrm{O}_{5}$ by a colorimetric method using spectrophotometer with micro flow-thru system (Spectoronic 100, Bausch \& Lomb Incorporation, Rochester, New York, USA) at $430 \mathrm{~nm}$.

\section{RESULTS AND DISCUSSION}

\section{Effect of acid type and demineralization conditions}

Table 2 shows the minerals composition of microbially deproteinized shells (MDS) and demineralized shells (DS) using hydrochloric, lactic and acetic acids under the two demineralization conditions described by Zakaria $^{[11]}$ and Ghanem et al. ${ }^{[12]}$ Figure 1 shows the removal efficiencies of the total minerals and calcium (the most abundant mineral in the shrimp shells) for the demineralized shells.

The total mineral content of the shrimp shells used in this study was $31.73 \%$. This value is within the range of $30-50 \%$ reported by Synowiecki and AlKateeb $^{[13]}$. The most abundant minerals in the shrimp shells were $\mathrm{Ca}, \mathrm{P}, \mathrm{Mg}, \mathrm{S}$ and $\mathrm{Na}$, which accounted for $44.75,7.06,1.94,1.48$ and $1.10 \%$ of the total shell mineral composition, respectively. The amount of calcium present in the shells was 6 and 23 times higher than the amounts of phosphorus and magnesium, respectively. Hansen and Illanes ${ }^{[14]}$ stated that the major mineral component of shellfish waste is calcium. Beaney et al. ${ }^{[15]}$ reported that the most abundant minerals in prawn shell were $\mathrm{Ca}, \mathrm{Mg}, \mathrm{Na}, \mathrm{Sr}, \mathrm{K}$ and $\mathrm{Fe}$ in that order and that calcium was by far the most abundant (about 17 times more calcium present than magnesium). Synowiecki and Al-Kateeb ${ }^{[13]}$ stated that the minerals fraction of shrimp shells composed mostly of phosphates and carbonates of calcium and magnesium.

In the microbially deproteinized shells (MDS), the total mineral composition was slightly reduced from 31.73 to $30.65 \%$. The reduction in calcium, sodium, sulfur, potassium and magnesium were $0.76,0.31,0.27$, 0.07 and $0.06 \%$, respectively. After the deproteinization process shrimp shells were washed with distilled deionized water until the wash water was clear. About $1.08 \%$ of the total minerals in the shells were removed in the wash water.

The results showed insignificant difference in the demineralization efficiency between conditions $\mathrm{A}^{[11]}$ and $\mathrm{B}^{[12]}$ when using $\mathrm{HCl}$. The total mineral content was reduced from the initial value of $30.65 \%$ in the MDS to final values of 3.15 and $3.26 \%$ in the DS for conditions $\mathrm{A}$ and $\mathrm{B}$, respectively. The calcium (the most abundant mineral in the shells) was reduced from the initial value of $13.44 \%$ in the MDS to final values of 0.12 and $0.13 \%$ in the DS for conditions A and B, respectively. In case of lactic acid, an insignificant difference in calcium removal was noticed between the two demineralization conditions (calcium concentration was reduced from the initial value of $13.44 \%$ in the MDS to final values of 0.78 and $0.70 \%$ in the DS for conditions $\mathrm{A}$ and $\mathrm{B}$, respectively). However, the reduction in the total mineral content differed slightly between the two demineralization conditions. The total mineral concentration was reduced from the initial value of $30.65 \%$ to final values of 3.69 and $4.60 \%$ for conditions $\mathrm{A}$ and $\mathrm{B}$, respectively.

The effectiveness of acetic acid in removing the minerals from the shells was lower than those of hydrochloric and lactic acids. The total minerals content was reduced from $30.65 \%$ in the MDS to 8.53 and 9.10 in the DS using acetic acid under conditions A and B,

Table 2: Effects of acid type and demineralization condition on minerals composition of demineralized shells

\begin{tabular}{|c|c|c|c|c|c|c|c|}
\hline \multirow{3}{*}{ Element } & \multirow{3}{*}{ MDS } & \multicolumn{6}{|c|}{ Concentration (\%) } \\
\hline & & \multicolumn{2}{|c|}{$\mathrm{HCl}$} & \multicolumn{2}{|c|}{ LA } & \multicolumn{2}{|c|}{$\mathrm{AC}$} \\
\hline & & $\mathrm{A}$ & $\mathrm{B}$ & $\mathrm{A}$ & $\mathrm{B}$ & $\mathrm{A}$ & $\mathrm{B}$ \\
\hline $\mathrm{Al}$ & 0.078 & 0.321 & 0.442 & 0.123 & 0.340 & 0.347 & 0.050 \\
\hline $\mathrm{Ca}$ & 13.439 & 0.115 & 0.132 & 0.784 & 0.702 & 3.216 & 4.030 \\
\hline $\mathrm{Cu}$ & 0.020 & 0.010 & 0.005 & 0.005 & 0.009 & 0.006 & 0.007 \\
\hline $\mathrm{Fe}$ & 0.056 & 0.172 & 0.059 & 0.053 & 0.209 & 0.111 & 0.051 \\
\hline $\mathrm{K}$ & 0.016 & 0.034 & 0.016 & 0.016 & 0.024 & 0.017 & 0.010 \\
\hline $\mathrm{Mg}$ & 0.555 & 0.047 & 0.035 & 0.030 & 0.072 & 0.049 & 0.030 \\
\hline $\mathrm{Mn}$ & 0.009 & 0.005 & 0.010 & 0.001 & 0.006 & 0.010 & 0.007 \\
\hline $\mathrm{Na}$ & 0.041 & 0.045 & 0.023 & 0.022 & 0.073 & 0.022 & 0.010 \\
\hline $\mathrm{P}$ & 2.860 & 0.046 & 0.083 & 0.534 & 0.410 & 1.685 & 1.630 \\
\hline $\mathrm{S}$ & 0.199 & 0.235 & 0.265 & 0.268 & 0.293 & 0.257 & 0.258 \\
\hline $\mathrm{Si}$ & 0.460 & 0.417 & 0.755 & 0.192 & 0.730 & 0.598 & 0.180 \\
\hline Others & 12.917 & 1.703 & 1.435 & 1.662 & 1.732 & 2.213 & 2.837 \\
\hline Total & 30.650 & 3.150 & 3.260 & 3.690 & 4.600 & 8.529 & 9.100 \\
\hline
\end{tabular}

MDS Microbially deproteinized shells

A - Temperature of $100^{\circ} \mathrm{C}$, shells to acid ratio of 1:50 and retention time of $1 \mathrm{~h}^{[11]}$

$\mathrm{B}$ - Temperature of $24^{\circ} \mathrm{C}$, shells to acid ratio of $1: 10$ and retention time of $6 \mathrm{~h}^{[12]}$ 


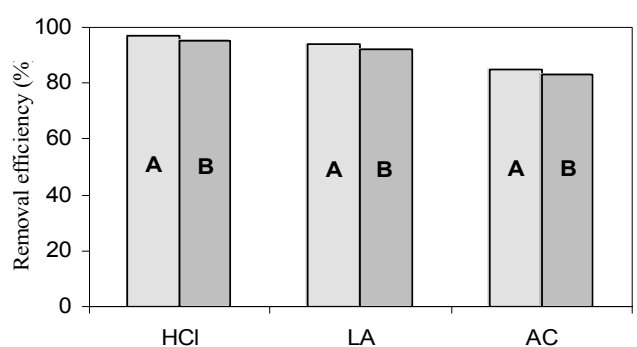

(a) Total minerals

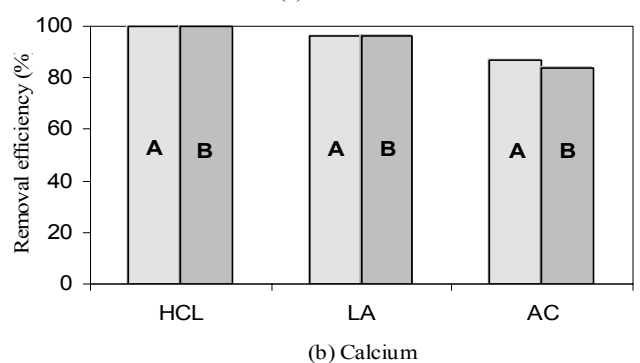

Fig. 1:Minerals removal efficiency for demineralized shells using hydrochloric acid $(\mathrm{HCl})$, lactic acid (LA) and acetic acid (AC) under two demineralization conditions (A: Temperature of $100{ }^{\circ} \mathrm{C}$, shells to acid ratio of $1: 50$ and retention time of $1 \mathrm{~h}$; B: Temperature of $24^{\circ} \mathrm{C}$, shells to acid ratio of 1:10 and retention time of $6 \mathrm{~h}$ )

espectively. The calcium concentration was reduced from $13.44 \%$ in the MDS to 3.22 and $4.03 \%$ in the DS using acetic acids under conditions $\mathrm{A}$ and $\mathrm{B}$, respectively.

The removal efficiencies of the total minerals and the calcium were calculated based on the microbially deproteinized sample weight and the recovered demineralized sample weight. The removal efficiencies of the total minerals and the calcium using demineralization condition A were 96.71 and $99.73 \%$, 94.07 and $97.13 \%$ and 85.56 and $87.59 \%$ for $\mathrm{HCl}$, LA and AC, respectively. The removal efficiencies of the total minerals and the calcium using demineralization condition B were 95.02 and $99.54 \%, 92.12$ and $97.26 \%$ and 82.55 and $82.38 \%$ for $\mathrm{HCl}, \mathrm{LA}$ and $\mathrm{AC}$, respectively. In general, insignificant differences between condition $\mathrm{A}$ and $\mathrm{B}$ were observed. The removal efficiencies using the three acids were acceptable although that of acetic acid was lower.

Zakaria et al. ${ }^{[16]}$ used lactic acid fermentation for chitin purification from Scampi waste and reported that approximately $61 \%$ of the calcium present in the scampi waste at the start of fermentation was solubilized and that the purified chitin contained about $19.3 \%$ calcium. Cira et al ${ }^{[17]}$ achieved reduction in calcium concentration from $14.6-15.9 \%$ to $6.3-8.1 \%$ during lactic acid fermentation of shrimp waste. Ghanem et al. ${ }^{[12]}$ studied the effect of various shrimp processing procedures on the quality and quantity of purified chitin and achieved reductions in the ash concentrations from 20.08 and $37.13 \%$ in the shrimp shells to 0.83 and $8.93 \%$ in the purified chitin for two shrimp shells, respectively. The calcium concentration was reduced from 3.56 to $2.38 \%$ and from 7.12 to $0.02 \%$ for the two shell types. Using lactic acid fermentation, Beaney et al. ${ }^{[15]}$ achieved reductions in the total inorganic matter and calcium concentrations from 61.8 to 19.6 and $14.2 \%$ and from 0.78 to 0.31 and $0.17 \%$, respectively. The authors also used $1 \mathrm{M} \mathrm{HCl}$ in a $1: 15$ shells to acid ratio for $2 \mathrm{~h}$ retention time at room temperature and achieved reduction in the total inorganic matter concentration from 61.8 to $0.2 \%$.

\section{Effect of retention time}

It was concluded that there was insignificant difference between the two tested conditions (A and $\mathrm{B}$ ). Therefore, condition $\mathrm{B}$ was used for further investigations since it saves energy and acid. Table 3 shows the minerals composition of microbially deproteinized shells (MDS) and Demineralized shells (DS) with lactic and acetic acids using demineralization procedure $\mathrm{B}$ (1:10 shells to acid ratio at room temperature) for 2 and $6 \mathrm{~h}$ retention times. Figure 2 shows the removal efficiencies of the total minerals and calcium for the demineralized shells.

The results showed that reducing the retention time from 6 to $2 \mathrm{~h}$ caused a slight reduction in minerals removal efficiency. The total mineral concentrations for 6 and $2 \mathrm{~h}$ retention times were 4.60 and 5.28\% and 9.10 and $11.39 \%$ for lactic and acetic acids, respectively. The calcium concentrations in the DS for 6 and $2 \mathrm{~h}$ retention times were 0.70 and $1.56 \%$ and 4.03 and 4.68 $\%$ for lactic and acetic acids, respectively. The total minerals removal efficiencies for 6 and $2 \mathrm{~h}$ retention times were 92.12 and $90.29 \%$ and 82.55 and $79.56 \%$ for lactic and acetic acids, respectively. The calcium removal efficiencies for 6 and $2 \mathrm{~h}$ retention times were 97.26 and $93.44 \%$ and 82.38 and $80.84 \%$ for lactic and acetic acids, respectively. A slight decrease in the removal efficiencies was observed when the retention time was reduced from 6 to $2 \mathrm{~h}$. However, lactic acid achieved higher removal efficiency than acetic acid.

There is a wide range of retention times $(0.5-48.0$ h) reported in the literature for the deproteinization of crustacean shells ${ }^{[18]}$. Retention time is one of the most important parameters in the demineralization process for chitin purification since prolonged retention times increase the cost and affects the quality of the purified chitin. Percot et al. ${ }^{[6]}$ reported that the quality of chitin and its effectiveness for different applications depend on the molecular weight distribution and the degree of acetylation. Synowiecki and Al-Kateeb ${ }^{[13]}$ reported that prolonged retention time may results in a slight drop in the mineral content but can cause significant chitin degradation. Madhavan and Nair ${ }^{[19]}$ reported a decrease 
Table 3: Effect of retention time on minerals composition of demineralized shells using different acids at room temperature

\begin{tabular}{|c|c|c|c|c|c|}
\hline \multirow{3}{*}{ Element } & \multirow{3}{*}{ MDS } & \multicolumn{4}{|c|}{ Concentration (\%) } \\
\hline & & \multicolumn{2}{|c|}{ LA } & \multicolumn{2}{|c|}{$\mathrm{AC}$} \\
\hline & & $6 \mathrm{~h}$ & $2 \mathrm{~h}$ & $6 \mathrm{~h}$ & $2 \mathrm{~h}$ \\
\hline $\mathrm{Al}$ & 0.078 & 0.340 & 0.356 & 0.050 & 0.332 \\
\hline $\mathrm{Ca}$ & 13.439 & 0.702 & 1.563 & 4.030 & 4.682 \\
\hline $\mathrm{Cu}$ & 0.020 & 0.009 & 0.014 & 0.007 & 0.012 \\
\hline $\mathrm{Fe}$ & 0.056 & 0.209 & 0.201 & 0.051 & 0.103 \\
\hline K & 0.016 & 0.024 & 0.012 & 0.010 & 0.033 \\
\hline $\mathrm{Mg}$ & 0.555 & 0.072 & 0.080 & 0.030 & 0.089 \\
\hline $\mathrm{Mn}$ & 0.009 & 0.006 & 0.004 & 0.007 & 0.008 \\
\hline $\mathrm{Na}$ & 0.041 & 0.073 & 0.117 & 0.010 & 0.034 \\
\hline $\mathrm{P}$ & 2.860 & 0.410 & 0.500 & 1.630 & 2.385 \\
\hline S & 0.199 & 0.293 & 0.243 & 0.258 & 0.252 \\
\hline $\mathrm{Si}$ & 0.460 & 0.730 & 0.817 & 0.180 & 0.506 \\
\hline Others & 12.917 & 1.732 & 1.372 & 2.837 & 2.952 \\
\hline Total & 30.650 & 4.600 & 5.279 & 9.100 & 11.388 \\
\hline
\end{tabular}

MDS Microbially deproteinized shells

AC Acetic acid

LA Lactic acid
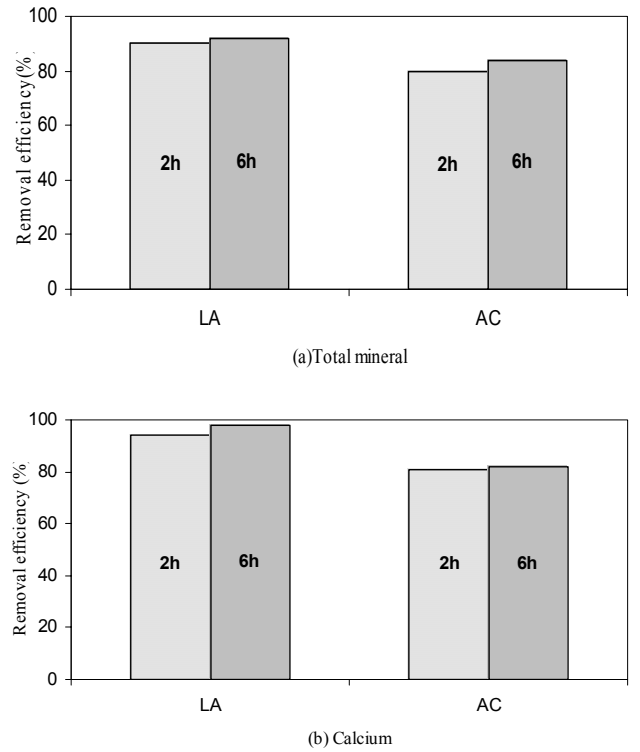

Fig. 2: Minerals removal efficiency for demineralized shells using lactic acid (LA) and acetic acid (AC) at room temperature at different retention times

in the viscosity of chitosan with the increase in treatment time in $\mathrm{HCl}$ as a result of the decrease of molecular weight with time. Percot et al. ${ }^{[6]}$ reported that the demineralization times reported in the literature are too long and recommended a retention time of $15 \mathrm{~min}$ using $0.25 \mathrm{M} \mathrm{HCl}$ with 1:40 shells to acid ratio.

\section{Effect of shell to acid ratio}

Table 4 shows the minerals composition of microbially deproteinized shells (MDS) demineralized with organic acids (lactic and acetic) using the modified demineralization procedure B (at room temperature) at $2 \mathrm{~h}$ retention time for 1:10, 1:20 and 1:30 shells to acid ratio. Figure 3 shows the removal efficiencies of the total minerals and calcium for the demineralized shells.
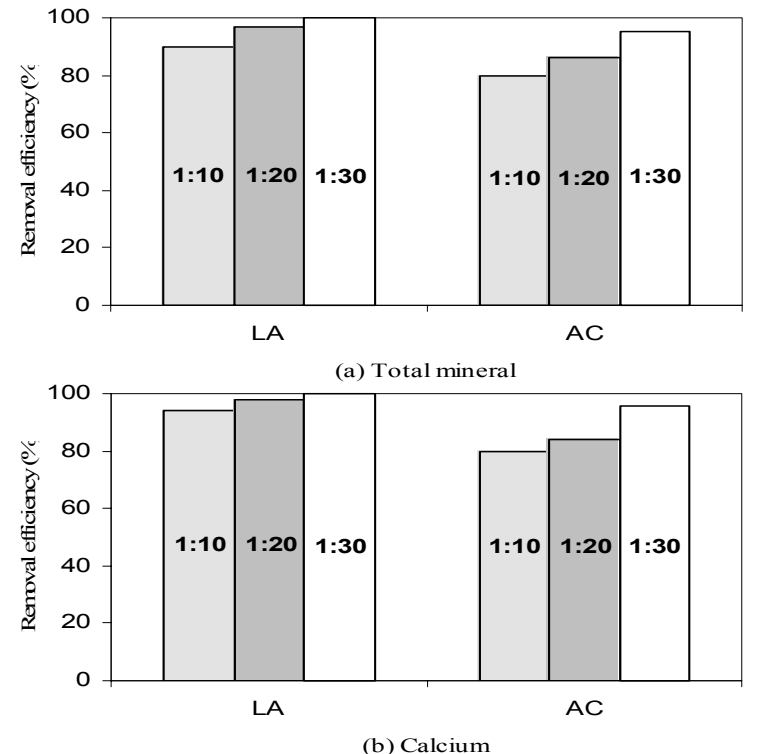

Fig. 3:Minerals removal efficiency for demineralized shells using hydrochloric acid ( $\mathrm{HCl})$, lactic acid (LA) and acetic acid (AC) at different retention times

The effect of acid to shells ratio (1:10, 1:20 and 1:30) was investigated using lactic and acetic acids at 2 $\mathrm{h}$ retention time. The results showed a significant increase in minerals removal when the shell to acid ratio was increased from 1:10 to 1:20. A further increase in the shells to acid ratio to 1:30 caused only a slight decrease in the mineral concentrations. When lactic acid was used, the total minerals concentrations in the demineralized shells (DS) were 5.28, 1.51 and $0.86 \%$ for $1: 10,1: 20$ and $1: 30$ shells to acid ratios, respectively. The calcium concentrations in the DS were $1.56,0.48$ and $0.10 \%$ for $1: 10,1: 20$ and $1: 30$ shells to acid ratios, respectively. The total minerals and calcium removal efficiencies were 90.29 and 93.44, 97.40 and 99.11 and 98.53 and $99.63 \%$ for 1:10, 1:20 and 1:30 shells to acid ratios, respectively. In the case 
Am. J. Biochem. \& Biotech. 3 (1): 1-9, 2007

Table 4: Effect of shells to acid ratio on minerals composition of demineralized shells

\begin{tabular}{|c|c|c|c|c|c|c|c|}
\hline \multirow{3}{*}{ Element } & \multirow{3}{*}{ MDS } & \multicolumn{6}{|c|}{ Concentration $(\%)$} \\
\hline & & \multicolumn{3}{|c|}{ LA } & \multicolumn{3}{|c|}{$\mathrm{AC}$} \\
\hline & & $1: 10$ & $1: 20$ & $1: 30$ & $1: 10$ & $1: 20$ & $1: 30$ \\
\hline $\mathrm{Al}$ & 0.078 & 0.356 & 0.065 & 0.040 & 0.332 & 0.150 & 0.163 \\
\hline $\mathrm{Ca}$ & 13.439 & 1.563 & 0.481 & 0.095 & 4.682 & 1.750 & 1.140 \\
\hline $\mathrm{Cu}$ & 0.020 & 0.014 & 0.003 & 0.003 & 0.012 & 0.003 & 0.003 \\
\hline $\mathrm{Fe}$ & 0.056 & 0.201 & 0.035 & 0.035 & 0.103 & 0.049 & 0.062 \\
\hline $\mathrm{K}$ & 0.016 & 0.012 & 0.011 & 0.015 & 0.033 & 0.010 & 0.010 \\
\hline $\mathrm{Mg}$ & 0.555 & 0.080 & 0.046 & 0.024 & 0.089 & 0.020 & 0.020 \\
\hline $\mathrm{Mn}$ & 0.009 & 0.004 & 0.002 & 0.001 & 0.008 & 0.007 & 0.006 \\
\hline $\mathrm{Na}$ & 0.041 & 0.117 & 0.014 & 0.015 & 0.034 & 0.020 & 0.010 \\
\hline $\mathrm{P}$ & 2.860 & 0.500 & 0.240 & 0.170 & 2.385 & 0.910 & 0.670 \\
\hline $\mathrm{S}$ & 0.199 & 0.243 & 0.244 & 0.246 & 0.252 & 0.280 & 0.256 \\
\hline $\mathrm{Si}$ & 0.460 & 0.817 & 0.252 & 0.164 & 0.506 & 0.310 & 0.590 \\
\hline Others & 12.917 & 1.372 & 0.115 & 0.054 & 2.952 & 0.201 & 0.140 \\
\hline Total & 30.650 & 5.279 & 1.509 & 0.862 & 11.388 & 3.710 & 3.070 \\
\hline \multicolumn{8}{|c|}{ MDS Microbially deproteinized shells } \\
\hline \multicolumn{8}{|c|}{ AC Acetic acid } \\
\hline \multicolumn{8}{|c|}{ LA Lactic acid } \\
\hline \multicolumn{8}{|c|}{ Retention time $=2 \mathrm{~h}$} \\
\hline \multicolumn{8}{|c|}{ Temperature $=24^{\circ} \mathrm{C}$} \\
\hline
\end{tabular}

of acetic acid, the total minerals concentrations in the DS were $11.39,3.71$ and $3.07 \%$ for $1: 10,1: 20$ and $1: 30$ shells to acid ratios, respectively. The calcium concentrations in the DS were $4.68,1.75$ and $1.14 \%$ for $1: 10,1: 20$ and 1:30 shells to acid ratios, respectively. The total minerals and calcium removal efficiencies were 79.56 and $80.84 \%, 86.36$ and $85.33 \%$ and 94.83 and $95.62 \%$ for $1: 10,1: 20$ and $1: 30$ shells to acid ratios, respectively.

There is a wide range (1:2 to greater than 1:40) of shells to acid ration reported in the literature for the demineralizatiom of crustacean shells ${ }^{[18]}$. Synowiecki and Al-Kateeb ${ }^{[13]}$ stated that full demineralization is possible when the amount of acid is stoichiometrically greater than the mineral content. Percot et al. ${ }^{[6]}$ studied the effect of shells to acid ratio on the demineralization of shrimp shells and recommended shells to acid ratio of 1:40 when using $0.25 \mathrm{M} \mathrm{HCl}$ for $15 \mathrm{~min}$ at room temperature.

Production of deicing agent/ food preservative Synowiecki and Al-Kateeb ${ }^{[13]}$ stated that a good chitin purification method should insure effective removal as well as utilization of other shell components. Alkaline salts of carboxylic acids had been found to have good de-icing ability ${ }^{[20-22]}$ as well as good antimicrobial activity $^{[23-24]}$. Acetate salts (mainly calcium, magnesium and potassium acetates) can be used as environmentally friendly de-icing agents and lactate salts (mainly calcium and potassium lactates) can be used as food preservatives.

Using lactic and/or acetic acids for the demineralization of shrimp shells would result in a solution containing a mixture of lactate and/or acetate salts. The most abundant salt in the resultant solution would be calcium lactate and/or calcium acetate since the calcium comprises about $44.75 \%$ of the total minerals present in the shrimp shells used in the current study. The ratio of $1 \mathrm{~g}$ shells to $20 \mathrm{~mL}$ acid was found reasonable for the demineralization of the shells. The total amount of acid used per kilogram shells on molar basis was 16.79 moles for lactic acid (90.07 $\mathrm{g} \mathrm{mol}^{-1}$ ) and 24.98 moles for acetic acid $\left(60.05 \mathrm{~g} \mathrm{~mol}^{-1}\right)$. Synowiecki and Al-Kateeb ${ }^{[13]}$ and Goycoolea et al. ${ }^{[25]}$ stated that the most important factor for the complete removal of minerals is to ensure that there is sufficient acid present (regardless of type), the minimum being at least stoichiometrically equal to the total amount of minerals present in the sample. Table 5 shows the minerals composition of the shrimp shells used in this study on a molar basis.

Although lactic acid was more effective for the demineralization process than acetic acid, there was no clear evidence found in the literature that proves the effectiveness of lactate salts for de-icing/anti-icing practices. In addition, the solubility of calcium lactate is significantly lower than the solubility of calcium acetate $\left(3.1\right.$ and $37.4 \mathrm{~g}$ salt per $100 \mathrm{~g}$ of water at $0{ }^{\circ} \mathrm{C}$ for calcium lactate and calcium acetate, respectively). The use of acetic acid for the demineralization process is more justified for the production of de-icing agent.

Numerous studies reported on the potentials of acetate salts especially calcium magnesium acetate(CMA) as a de-icing agent. In 1979,calcium magnesium acetate was identified as a non-corrosive environmentally-friendly alternative to chloride salts for road de-icing practices ${ }^{[26]}$. The major disadvantage of CMA is its relatively high production cost, which is mainly attributed to the cost of acetic acid ${ }^{[27]}$. Yang et $a l .{ }^{[28]}$ stated that acetic acid used to produce calcium magnesium acetate, as a road de-icer, pure as acetic acid used in the chemical industry. Producing acetic acid from cheese whey could reduce its production cost significantly. The use of acetic acid for the demineralization of shrimp shells in the ratio of $1 \mathrm{~g}$ 
Am. J. Biochem. \& Biotech. 3 (1): 1-9, 2007

\begin{tabular}{|c|c|c|c|c|c|}
\hline \multirow{2}{*}{ Element } & \multirow{2}{*}{ Valance } & \multirow{2}{*}{ Molecular weight } & \multicolumn{3}{|c|}{ Concentration $^{\mathrm{a}}$} \\
\hline & & & $\%^{\mathrm{b}}$ & $\mathrm{g} \mathrm{kg}^{-1}$ & $\mathrm{~mol} \mathrm{~kg}^{-1}$ \\
\hline $\mathrm{Al}$ & +3 & 26.982 & 0.08 & 0.250 & 0.0093 \\
\hline $\mathrm{Ca}$ & +2 & 40.078 & 44.75 & 142.000 & 3.5431 \\
\hline $\mathrm{Cu}$ & $+1,+2$ & 63.546 & 0.01 & 0.024 & 0.0004 \\
\hline $\mathrm{Fe}$ & $+2,+3$ & 55.845 & 0.10 & 0.308 & 0.0055 \\
\hline $\mathrm{K}$ & +1 & 39.098 & 0.27 & 0.871 & 0.0223 \\
\hline $\mathrm{Mg}$ & +2 & 24.305 & 1.94 & 6.150 & 0.2530 \\
\hline $\mathrm{Mn}$ & $+2,+3,+4,+7$ & 54.938 & 0.04 & 0.116 & 0.0021 \\
\hline $\mathrm{Na}$ & +1 & 22.990 & 1.10 & 3.480 & 0.1514 \\
\hline $\mathrm{P}$ & $+3,+5,-3$ & 30.974 & 7.06 & 22.400 & 0.7232 \\
\hline $\mathrm{S}$ & $-2,+4,+6$ & 32.065 & 1.48 & 4.700 & 0.1466 \\
\hline $\mathrm{Si}$ & $-4,+2,+4$ & 28.086 & 0.25 & 0.794 & 0.0283 \\
\hline
\end{tabular}

${ }^{a}$ total mineral concentration in the shrimp shells was $317.3 \mathrm{~g}$ minerals per $\mathrm{kg}$ shells

${ }^{\mathrm{b}}$ percent of the total mineral content

Table 6: Solubilities $^{\mathrm{a}}$ of some salts in water at various temperatures ${ }^{[29]}$

\begin{tabular}{|c|c|c|c|c|c|c|c|}
\hline \multirow{2}{*}{ Substance } & \multirow{2}{*}{ Formula } & \multicolumn{6}{|c|}{ Temperature $\left({ }^{\circ} \mathrm{C}\right)$} \\
\hline & & 0 & 10 & 20 & 30 & 40 & 60 \\
\hline Sodium chloride & $\mathrm{NaCl}$ & 35.7 & 35.8 & 35.9 & 36.1 & 36.4 & 37.1 \\
\hline Calcium lactate & $\mathrm{Ca}\left(\mathrm{C}_{3} \mathrm{H}_{5} \mathrm{O}_{3}\right)_{2} .5 \mathrm{H}_{2} \mathrm{O}$ & 3.1 & & $5.4^{15^{\circ}}$ & 7.9 & & \\
\hline Calcium acetate & $\mathrm{Ca}(\mathrm{OAc})_{2} \cdot 2 \mathrm{H}_{2} \mathrm{O}$ & 37.4 & 36.0 & 34.7 & 33.8 & 33.2 & 32.7 \\
\hline Magnesium acetate & $\mathrm{Mg}\left(\mathrm{C}_{2} \mathrm{H}_{3} \mathrm{O} 2\right)_{2}$ & 56.7 & 59.7 & 53.4 & 68.6 & 75.7 & 118 \\
\hline Potassium acetate & $\mathrm{KC}_{2} \mathrm{H}_{3} \mathrm{O}_{2}$ & 216 & 233 & 256 & 283 & 325 & 350 \\
\hline Sodium acetate & $\mathrm{NaC}_{2} \mathrm{H}_{3} \mathrm{O}_{2}$ & 36.2 & 40.8 & 46.4 & 54.6 & 65.6 & 139 \\
\hline
\end{tabular}

shells: $20 \mathrm{~mL}$ acetic acid would result in $560.38 \mathrm{~g}$ calcium acetate per $1 \mathrm{~kg}$ shells. The process could be described by the following equations

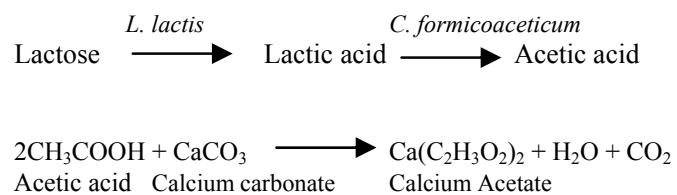

Dionysiou et $a .^{[27]}$ stated that the following reactions can occur:

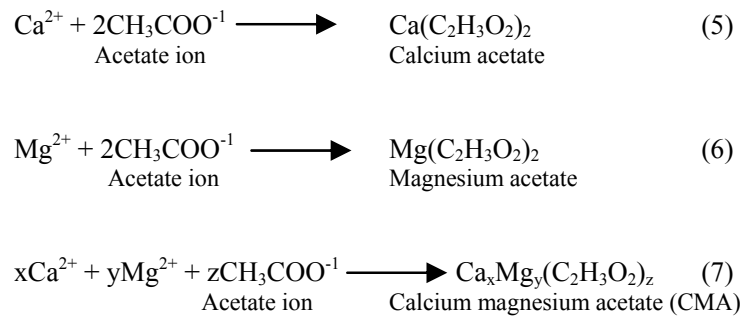

Marynowski et al. ${ }^{[26]}$ reported that liquid potassium acetate is being used now for airport runways de-icing practices. The use of acetic acid for the demineralization of shrimp shells in the ratio of $1 \mathrm{~g}$ shells: $20 \mathrm{~mL}$ acetic acid would result in $2.19 \mathrm{~g}$ potassium acetate per $1 \mathrm{~kg}$ shells.

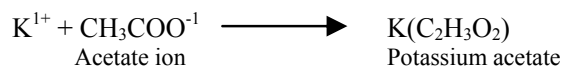

Bang and Johnston ${ }^{[21]}$ stated that a deicing agent is known to be more effective when it has a lower molecular weight with higher solubility. Table 6 shows the solubilities of sodium chloride,calcium lactate and some acetate salts. Sodium chloride is commonly used for ice control practices. However, concerns regarding corrosion and adverse environmental effects associated with the use of sodium chloride prompted the evaluation of organic salts. The solubility of calcium lactate is very low compared to sodium chloride. The solubilities of acetate salts are comparable to the solubility of sodium chloride. The use of lactic acid for the demineralization of shrimp shells in the ratio of $1 \mathrm{~g}$ shells: $20 \mathrm{~mL}$ lactic acid would result in $773.17 \mathrm{~g}$ calcium lactate per $1 \mathrm{~kg}$ shells, according to the following equation:

$\begin{aligned} & 2 \mathrm{C}_{3} \mathrm{H}_{6} \mathrm{O}_{3}+\mathrm{CaCO}_{3} \\ & \text { Lactic acid }+ \text { Calcium carbonate }\end{aligned} \underset{\text { Calcium lactate }}{\mathrm{Ca}\left(\mathrm{C}_{3} \mathrm{H}_{5} \mathrm{O}_{3}\right)_{2}}+\mathrm{H}_{2} \mathrm{O}+\mathrm{CO}_{2}$

\section{CONCLUSION}

The study showed that the effectiveness of organic acids (lactic and acetic) for the demineralization of shrimp shells was comparable to that of hydrochloric acid. For effective removal of minerals from shrimp shells using organic acids (lactic and acetic), shells to acid ratio of 1:20, temperature of $24{ }^{\circ} \mathrm{C}$ (room temperature) and retention time of $2 \mathrm{~h}$ were found satisfactory. Under these conditions, the total minerals and calcium removal efficiencies were 97.4 and $99.11 \%$ and 86.36 and $85.33 \%$ for lactic and acetic acids, respectively. Using acetic acid in the ratio of 1:20 g shells to $\mathrm{mL}$ acid for the demineralization of shrimp shells would result in the production of $560.38 \mathrm{~g}$ 
calcium acetate and $2.19 \mathrm{~g}$ potassium acetate for each 1 $\mathrm{kg}$ shells if all the calcium and potassium present in the shrimp shells are removed. Using lactic acid in the ratio of 1:20 g shells to $\mathrm{mL}$ acid for the demineralization of shrimp shells would result in the production of $773.17 \mathrm{~g}$ calcium acetate for each $1 \mathrm{~kg}$ shells if all the calcium present in the shrimp shells is removed. Using organic acids for the demineralization of shrimp shells would result in: (a) effective removal of minerals, (b) reduction in the purification cost, (c) preservation of natural chitin characteristics and (d) production of value added products (food preservatives and/or de-icing agents) besides the purified chitin.

\section{ACKNOWLEDGEMENT}

This project was funded by the National Science and Engineering Council (NSERC) of Canada. The financial support provided by Dalhousie University Faculty of Graduate Studies is highly appreciated.

\section{REFERENCES}

1. Li, Q., E.T. Dunn, E.W. Grandmaison and M.F.A. Goosen, 1997. Applications and Properties of Chitin and Chitosan. In Applications of Chitin and Chitosan, Ed. Mattheus F.A. Goosen, pp; 3-29. Pennsylvania: Technomic Publishing Company.

2. Brzeski, M.M., 1987. Chitin and chitosan - putting waste to good use. INFOFISH Intl., 5: 38-40.

3. Gagné, N. and B.K. Simpson, 1993. Use of proteolytic enzymes to facilitate the recovery of chitin from shrimp wastes. Food Biotechnol., 7: 253-263.

4. Abdullah, M.P., 1995. The Production of Chitin and Chitosan in Malaysia and the Potential Use of Chitosan in the Treatment of Oily Water Discharges. In Chitin and Chitosan the Versatile Environmentally Friendly Modern Materials. Eds. Zakaria, M.B., W.M.W. Muda and M.P. Abdullah, Malaysia: Universiti Kebangsaan Malaysia.

5. Subasinghe, S., 1995. The Development of Crustacean and Mollusk Industries for Chitin and Chitosan Resources. In Chitin and Chitosan the Versatile Environmentally Friendly Modern Materials. Zakaria, M.B., W. M.W. Muda and M.P. Abdullah, pp: 27-34. Malaysia: Universiti Kebangsaan Malaysia.

6. Percot, A., C. Viton and A. Domard, 2003. Optimization of chitin extraction from shrimp shells. Biomacromolecules, 4:12-18.

7. Shahidi, F. and J. Synowiecki, 1992. Quality and Compositional Characteristics of Newfoundland Shellfish Processing Discards. In Advances in Chitin and Chitosan, Eds. Brine, C.J., P.A. Sanford and J.P. Zikakis, pp: 617-626. England: Elsevier Applied Science.

8. Mahmoud, N.S., 2005. Novel biotechnological approach for the production of chitin and de-icing agents. Unpublished Ph.D. Thesis. Halifax, NS: Department of Biological Engineering, Dalhousie University.

9. Tango, S.A. and A.E. Ghaly, 2002. A continuous lactic acid production system using an immobilized packed bed of Lactobacillus helveticus. Appl. Microbiol. Biotechnol., 58: 712-720.

10. Yang, S.T., Y.L. Huang, Z. Jin, Y. Huang, H. Zhu and W. Qin, 1999. Calcium magnesium acetate at lowerproduction cost: production of CMA deicer from cheese whey. U.S. Department of Transportation, Federal Highway Administration, FHWA-RD-98-174.
11. Zakaria, Z., 1997. Lactic acid purification of chitin from prawn waste using a horizontal rotating bioreactor. Unpublished Ph.D. Thesis. Loughborough, UK: Loughborough University.

12. Ghanem, A., A.E. Ghaly and M. Chaulk, 2003. Effect of shrimp processing procedures on the quality and quantity of extracted chitin from the shells of northern shrimp Pandalus borealis. J. Aquat. Food Prod. Technol., 12: 63-79.

13. Synowiecki, J. and N.A. Al-Khateeb, 2003. Production, properties and some new applications of chitin and its derivatives. Crit. Rev. Food Sci. Nutr., 43: 145-171.

14. Hansen, M.E. and A. Illanes, 1994. Applications of Crustacean Wastes in Biotechnology. In Fisheries Processing: Biotechnological Applications, Ed. Martin, A. M. London, UK: Chapman \& Hall.

15. Beaney, P., J.L. Mendoza and M. Healy, 2005. Comparison of chitins produced by chemical and bioprocessing methods. J. Chem. Technol. Biotechnol., 80: $145-150$.

16. Zakaria, Z., G.M. Hall and G. Shama, 1998. Lactic acid fermentation of scampi waste in a rotating horizontal bioreactor for chitin recovery. Process Biochem., 33: 1-6.

17. Cira, L.A., S. Huerta, G.M. Hall and K. Shirai, 2002. Pilot scale lactic acid fermentation of shrimp wastes for chitin recovery. Process Biochem., 37: 1359-1366.

18. No, H.K. and S.P. Meyers, 1995. Preparation and characterization of chitin and chitosan- A review. J. Aquat. Food Product Technol., 4: 27-52.

19. Madhavan, P. and K.G.R. Nair, 1974. Utilization of prawn waste: Isolation of chitin and its conversion to chitosan. Fish. Technol., 11: 50.

20. Ketcham, S.A., L.D. Minsk, R.R. Blackburn and E.J. Fleege, 1996. Manual of practice for an effective antiicing program: A guide for highway winter maintenance personnel. Report No. FHWA-RD-95-202. Hanover, New Hampshire: US Army Cold Regions Research and Engineering Laboratory.

21. Bang, S.S. and D. Johnston, 1998. Environmental effects of sodium acetate/formate deicer, Ice Shear ${ }^{\mathrm{TM}}$. Arch. Environ. Contamin. Toxicol., 35: 580-587.

22. Jin, F., A. Kishita, T. Moriya, H. Enomoto and N. Sato, 2002. A new process for producing $\mathrm{Ca} / \mathrm{Mg}$ acetate deicer with $\mathrm{Ca} / \mathrm{Mg}$ waste and acetic acid produced by wet oxidation of organic waste. Chem. Lett., 1: 88-89.

23. Shelef, L.A., 1994. Antimicrobial effects of lactates - a review. J. Food Prot., 57: 445-450.

24. Pattison, T.L. and A. von Holly, 2001. Effect of selected natural antimicrobials on backer's yeast activity. Lett. Appl. Microbiol., 33: 211-215.

25. Goycoolea, F.M., W. Arguelles-Monal, C. Peniche and I. Higuera-Ciapara, 2000. Chitin and chitosan. In Novel Macromolecules in Food Systems, Eds. Doxastakis G. and V. Kiosseoglou, pp: 265-308. Elsevier Science.

26. Marynowski, C.W., J.L. Jones, D. Tuse and R.L. Boughton, 1985. Fermentation as an advantageous route for the production of an acetate salt for roadway deicing. Indust. Engg. Chem. Prod. Res. Develop., 24: 457465 .

27. Dionysiou, D.D., M. Tsianou and G.D. Botsaris, 2000. Investigation for conditions for the production of calcium magnesium acetate (CMA) road deicer in an extractive crystallization process. Crystal Res. Technol., 35: 1035-1049.

28. Yang, S.T., I.C. Tang and H. Zhu, 1992. A novel fermentation process for calcium magnesium acetate (CMA) production from cheese whey. Appl. Biochem. Biotechnol., 34-35: 569-583.

29. Dean, J.A., 1999. Lange's Handbook of Chemistry. $15^{\text {th }}$ Edn. New York, NY: MacGraw-Hill Inc. 